\title{
Communicative Figurations and Cross-Media Research
}

\author{
Kim Christian Schrøder
}

\subsection{INTRODUCTION}

What do urban young people's media-anchored communities, a national hacker non-governmental organization (NGO), repair cafés, DIY maker networks, a city's media ensemble, secondary classes in a local school, national news publics, a financial blogging community, the Roman Catholic Church in Germany, political decision meetings and secondary school administrations have in common?

Well, according to this edited volume what all these mediated collectivities have in common is their status as 'communicative figurations', which should be analyzed empirically in a cross-media perspective for the common purpose of better understanding how communications landscapes are transforming in times of deep mediatization, and how they influence wider social and cultural processes.

It is great that a concept which has been theoretically described and analytically exemplified frequently but sporadically in the mediatization

K.C. Schrøder $(\square)$

Department of Communication and Arts, Roskilde University, Roskilde, Denmark e-mail: kimsc@ruc.dk

(c) The Author(s) 2018 407

A. Hepp et al. (eds.), Communicative Figurations, Transforming Communications - Studies in Cross-Media Research, https://doi.org/10.1007/978-3-319-65584-0_17 
literature in recent years has been given a full volume that is dedicated to showing its potential, not just as a helpful heuristic but as a mature theoretical construct which can be operationalized to orchestrate many kinds of empirical research in the mediatized culture. Perhaps, as the insights provided by the contributions to this volume make their impact on scholarly debates about mediatization, the time will come to start reflecting on ways to further sharpen the concept of communicative figuration, when operationalizing its conceptual inventory for empirical research, as media technologies and contents continue to play pivotal influential roles in the wider processes of cultural, political and social transformation.

This postscript is intended to reflect on the accomplishments of figurational media research so far, and to discuss some of the paths along which such clarification and development may occur, in the service of further developing an evidently very useful heuristic lens into an even more rigorous analytical concept.

\subsection{Communicative Figurations as Constitutive of Mediatization}

In a research seminar three or four years ago I was applauding the merits of mediatization theory as a promising way, not contaminated by 'effects research', to conceptualize the influence of media on the ongoing transformations of culture and society. An experienced news media researcher, a trifle condescendingly, then remarked: 'I am not a member of that congregation!'. The beauty of the concept of communicative figuration as I see it is that you don't have to be a member of 'the mediatization congregation' in order to embrace it theoretically and to apply it to orchestrate a wide range of different research endeavours about cross-media practices.

Of course, as laid out by Andreas Hepp and Uwe Hasebrink in the book's foundational Chap. 2 (and in numerous earlier publications, for instance Hepp 2013, 2014), the concept 'communicative configuration' does have its origins within what has been termed the constructionist variety of mediatization research, where the concept has a particular role to play in the empirical investigation of 'deep' mediatization processes.

In their theoretical introduction to this volume, Hepp and Hasebrink argue that the study of how media influence social processes has become more complicated as a result of the rapidly evolving media manifold (Couldry 2012: 44), life with polymedia (Madianou 2014) and so on. 
As a result of the intensifying processes of digitization and datafication, media are changing communication in historically unprecedented ways, with profound implications for the 'communicative construction of reality' under conditions of deep mediatization (Couldry and Hepp 2016). In order to understand the mediatized culture, our research efforts should be directed towards the specific 'domains' in which social transformations are played out, as a consequence of complex social forces, one of which is coming from the communications media.

Incidentally, this insistence on domain specificity also serves to demarcate Hepp and Hasebrink's 'constructivist' brand of mediatization theory from so-called 'institutionalist' mediatization theory, which sees the media as an independent societal institution (Strömbäck 2008; Hjarvard 2013): Hepp and Hasebrink see it as less helpful to understand (mass) media as a domain of its own, because under conditions of deep mediatization 'digital media permeate the various domains of society', making it less appropriate 'to see them as a domain of their own' (Hepp and Hasebrink, Chap. 2). In other words, because 'the media' are inherently a cross-domain phenomenon, they should not be conceptualized as one institution to be studied in order to understand the stage of deep mediatization. Instead we must look at domains not defined in media terms and see how cross-media ensembles function in these domains, with agency and social practice in the foreground.

This is where communicative figurations become relevant: the relevant domains can be analyzed empirically through the heuristic lens of communicative figurations: "This means a perspective that moves the figurations of human actors into the foreground and at the same time takes into account how far these figurations are entangled with media as contents and technologies, which on a deeper level refers both to media organizations and infrastructures" (Hepp and Hasebrink, Chap. 2). Communicative figurations can thus be understood as a domain-specific recipe for researching mediatization processes empirically - they are a conceptual tool for describing "in detail how the transformation that we relate to the term mediatization actually takes place" (Hepp and Hasebrink, Chap. 2).

Chapter 2 thus paves the way for the dozen case studies in the following chapters, by brilliantly unfolding in an accessible way (see for instance the model in Fig. 2.1:31) how the complex conceptual territory of mediatization theory can be encapsulated in a model of how the defining trends of deep mediatization (differentiation, connectivity, omnipresence, pace of innovation, datafication) are played out in social domains. 
These domains are then conceptualized as communicative figurations, with possible internal and external consequences, such as changing hierarchies of authority, modes of participation, blurring boundaries between media producers and recipients, social surveillance, social inclusions and exclusions, and so on.

Within this overall matrix for understanding mediatization, communicative figurations are defined, with inspiration from Norbert Elias, in terms of their constellation of actors, their frames of relevance and their communicative practices. In addition to their non-mediated face-to-face communicative practices, communicative figurations are heavily populated with media. Again, the media aspect is rigorously conceptualized on three levels: as the entire media environment, available at a given point in time, as the media ensemble which is the subset of media used in a particular social domain, and as the media repertoire appropriated by the individual across the relevant social domains of his/her everyday life. Communicative figurations thus provide a bridge between research that defines media repertoires according to social domains such as the workplace, the family, commuter transport and so on (Taneja et al. 2012) and those who analyze the media repertoires of individuals (Helles et al. 2015; Kobbernagel and Schrøder 2016). And-like media audiencesthey are inherently a cross-media phenomenon (Schrøder 2011).

A further definitional characteristic of communicative figurations is their scalability, from the smallest everyday grouping, such as a family or a municipal committee, to the largest (supra)national collectivity, such as a country's public sphere, or the global financial market (Couldry and Hepp 2016). This has the advantage of providing analytical flexibility to the application of communicative figurations (any social grouping or area can be nominated for analysis as a communicative figuration), but it also comes with a blurriness that risks diluting the concept (Hepp and Hasebrink, Chap. 2). I shall return to this issue later.

Another challenge for research into communicative figurations stems from the inherent porousness of the boundaries between communicative figurations, both within the micro, meso- and macro-levels and between these levels. This is not so much a theoretical challenge as a methodological and empirical challenge: one can easily grasp theoretically that 'figurations of social domains are interrelated in various ways' (Hepp and Hasebrink, Chap. 2), for instance in terms of their overlapping actor constellations. Similarly, 'figurations of collectivities and organizations 
can become "supra-individual actors" [...] that are part of the actor constellation of other figurations and thus build "figurations of figurations" (Hepp and Hasebrink, Chap. 2). However, with one or two exceptions, the case studies in the volume do not attempt to systematically operationalize such figurational embeddedness for empirical investigation, which would probably also be quite staggering in methodological terms. However, even without empirical anchoring of this added level of complexity, the volume collectively represents a major step forward in the pursuit of analytical insights about our increasingly and excitingly mediatized culture.

\subsection{A Selection from the Buffet of Communicative Figurations}

The 12 empirical chapters demonstrate through their extremely varied choice of social domains and communicative figurations how the concept of communicative figurations can be applied as a heuristic framework for producing insights about the ways in which 'our social domains are moulded by media' (Hepp and Hasebrink, Chap. 2), or rather-if we adhere to a strict practice theoretical perspective-how these social domains are moulded by the practices in which social actors are using media to achieve their mundane, professional and political ends: 'The concept of figurations links a micro-analysis of individual practices with a meso-analysis of certain social domains and thus offers us various possibilities to contextualize this with macro questions about society' (Hepp and Hasebrink, Chap. 2). The study in Chap. 13 by Andreas Breiter and Arne Hendrik Ruhe is a case in point: Applying the core concepts of figurational theory, their chapter shows how the figurational framework can be used to rigorously map the mediated managerial governance structures of German and English schools. The analysis focuses on the meso (organizational) level, its media ensemble and the role of management information systems, but in order to do so analyzes the media repertoires of individual teachers and administrators, ${ }^{1}$ and also anchors the communicative practices discovered in the macro national educational governance systems in the two countries: "The school's media ensemble is a moulding force for changes in communicative practices within the actor constellation of schools, among staff, students and administrators as well as in contact with parents" (Breiter and Ruhe, Chap. 13). 
It is striking how all chapters are very explicit about their adherence to the theoretical framework laid out by the editors' introduction (for an exceptionally elaborate and graphic use of the full conceptual inventory of cross-media practices and actor constellations, see the comparative case study of online gamers and DIY groups by Wolf and Wudarski, Chap. 6; see also Friemel and Bixler, Chap. 8). Because the chapters apply the conceptual framework so literally, one could say that collectively they really serve as a variegated and successful test bed for the ability of the concept of communicative figurations to serve as an eyeopening descriptive and explanatory lens through which we can see how our social reality is constructed in and through such communicative figurations.

Andreas Hepp, Piet Simon and Monika Sowinska's chapter about young people's urban communities (Chap. 3) may serve as an illustration of the way the figurational approach can illuminate the communicative practices of small-scale cross-media collectivities (groups of friends). Asking what extensive mediatization means to young people in their daily urban sense of community, and defining media as both technologies and content, the authors studied young people's cross-media urban communities in two mediated cities (Leipzig, Bremen). The methodological design consisted of qualitative interviews with 60 youths and ethnographic observation of selected urban locations. These communities were studied as three interrelated communicative figurations: friendship groups, urban locations (shopping mall, cinema, Hackerspace) and the level of imagined communities (i.e. how the young people feel attached to their city). Faced with the paradox that 'not every young person for whom the city is an important space of opportunity for community thinks the city as imagined community to be very important' (73), the analysis identified four 'horizons of communitization': localists, centrists, multi-localists and pluralists (73). Interestingly, irrespective of their degree of allegiance to the city, '[a]ll of those we interviewed ranked their group of friends very much above the city' (75). Overall the chapter shows how the theoretical framework of communicative figurations and mediatization can be used productively to study how young people make sense of their cross-media lives in the mediated city: it demonstrates 'the degree to which for young urban dwellers-besides family, acquaintances and colleagues - it is their network of friends that remains the primary figuration of their experience of community construction. And this has become to a very great degree a mediatized phenomenon' 
(52) It is an interesting insight that the full cross-media potential of the young people's available media ensemble is almost neutralized by the normative pressure within the group to use one form of media: Facebook.

Chapter 4 by Sebastian Kubitschko takes figurational analysis into the area of civil society organizations, as he analyzes the German national hacker organization The Chaos Computer Club as a communicative figuration. The research question, how does the Chaos Computer Club communicatively construct media technologies and infrastructures as a political category in its own right, aims to understand how one of the world's oldest and largest hacker organization's 'political engagement today relies on a wide range of practices related to media technologies and infrastructures and, at the same time, continues to be oriented towards larger publics as well as "traditional" centres of political power' (82). The methodological design takes the form of an extended case study that brings together data from 40 face-to-face interviews with Club members and participant observation of internal and public gatherings, contextualizing these with insights from a wide range of media discourses (such as the Club magazine, its official Twitter account, mainstream media coverage of prominent hacks). The analysis uses the figurational lens to create historical insights about the organizations changing actor constellations, communicative practices and political frames of relevance, showing how the organization has been a transformative force, achieving and maintaining socio-political influence through its media ensemble and its cross-media communicative practices. More generally, the analysis shows how communicative figurations can be a useful sensitizing concept for structuring an empirical analysis that maps the communicative context around a politically oriented organization.

Chapter 9 by Leif Kramp and Wiebke Loosen takes us into the realm of the national public sphere, as they use the figurational mindset in the service of substantiating media-related cultural transformations in a diverse, cross-media news ecology. The complete figurational mindset is encapsulated in a visual model (208), as they explore how journalistic role conceptions are being adapted to a transforming news landscape. Here journalists are struggling to find their professional feet on the continuum from traditional legacy news media ideals of gatekeeper and watchdog, to the more participatory, dialogic ideals of a platform-diverse news universe increasingly colonized by social media and the 'omnipresence of audience feedback' (206). Drawing on previously conducted 
empirical research, ${ }^{2}$ their comparative study of the actor constellation of news producers and news audiences shows how the emerging new role orientations (conceptualized as the figuration's frame of relevance) are the outcome of complex mutual expectations among journalists and citizen audiences. The study thus shows how the figurational approach is not just suitable for analyzing actor constellations characterized by the proximity of actors in small groups or organizations, but how the producer/recipient nexus of mass-mediated communication across a spatio-temporal distance can be conceptualized and operationalized as a communicative figuration on a national scale.

\subsection{When is Something (Not) a Communicative Figuration?}

There are a couple of studies in this volume which are insightful in their own terms, but which I have some difficulty in seeing as entirely felicitous analyses of communicative figurations. Perhaps there is a risk at this point that communicative figuration research is encountering a 'bandwagon effect': the terminological inventory that comes with communicative figurations offers a systematic, heuristic vocabulary that many are tempted to associate their research with, although strictly speaking the theoretical and analytical tools of the figurational approach are not fully compatible with the research question.

For instance, in their interesting study of the attempts in the 1950s of Hamburg and Leipzig to brand themselves as urban spaces of identity, in a process of 'urban collectivity building', in Chap. 7, Yvonne Robel and Inge Marszolek recognize that ' $[\ldots]$ the concept of figuration exhibits a strong bias to the investigation of communicative practices. However, not only individuals are involved in these communicative practices but also collectivities and organizations.' On this basis, they argue that it is justified to ask about the role of the cities' media organization for the 'collective processes of identity building', and their analysis accordingly applies a cross-media critical discourse analysis of the two cities' broadcasting and electronic media content, considering significant metaphors which position the cities in different ways as a 'bridge to the world' (Leipzig) and 'gateway to the world' (Hamburg). However, my problem is that we are not presented with an actor constellation whose negotiations, contestations and concerted efforts can be said to have resulted in the 'communicative practices' (or simply 'contents') disseminated by the 
media. Moreover, the analysis is framed by references to 'deep mediatization', in spite of the fact that this era is a phenomenon of the twentyfirst century. In other words, maybe the figurational framework is here grafted onto a fairly straightforward discourse analysis of the media representation of cities?

Similarly, in their insightful discourse analysis of how deliberative and moralizing norms and values around the causes and consequences of the financial crisis are communicatively constructed on four financial blogs, in Chap. 10, Rebecca Venema and Stephanie Averbeck-Lietz position their analysis within the figurational approach: 'The figurational approach $[\ldots]$ offered the chance for an integrative, cross-media analysis of crisis-related normative controversies, while reflecting on the specific interplay of actors, practices and structures characterizing and moulding these processes' (256). They analyze a 'media ensemble' of four blogs populated by an 'actor constellation' of three prominent bloggers and a multi-author group, some of whom are specialized journalists while others are financial experts. This actor constellation is characterized as 'a specific and dynamic collectivity of debate emerging in cross-media debates on the crisis' (247). However, it is not clear in what sense these three types of actors, who write for four selected blogs, can be seen as a 'collectivity' or an actor constellation. Is it not rather that they have been sampled to represent a much larger communicative figuration, or domain, of financial reporting and debate, with a much larger actor constellation, which should have been considered analytically in order to justify the claim of having analyzed a communicative figuration?

A related objection could be raised against the claim that the analyzed debates 'are primarily situated in a specific media ensemble: the aforementioned blogs' (249). It is not evident in what sense the four selected blogs constitute a media ensemble, apart from having been selected by the authors for analytical scrutiny. The authors describe how the blog debates 'are related to the figurations of other publics [...], including for example expert journals or newspapers and television coverage about the crisis' (249), and state that one blog in particular 'connects to other blogs as well as national and international mass and specialist media' (249). In order to qualify as an analysis of a 'communicative figuration', it could be said that the analysis should have encompassed (at least parts of) the interdiscursive media ensemble, and not just the four blogs. It is thus not evident to me how this discourse analysis of a sample of blog debates about the 2008 financial crisis qualifies as an example of the application of the figurational framework. 
I was also puzzled by the way in which the study by Tanja PritzlaffScheele and Frank Nullmeier, Chap. 12, analyzed its communicative figuration of political decision-making meetings by proxy, projecting the findings from an experimental laboratory on to the real-life setting of political decision-making. The aim of the study was to explore why politicians continue to prefer face-to-face settings for their decision meetings, at a time when most other areas of political communication are becoming mediatized. Instead of analyzing genuine communicative figuration of decision-making, Pritzlaff-Scheele and Nullmeier conducted micro-ethnographic analysis comparing, on the one hand, face-to-face group experiments in which participants communicated naturally with speech-body acts, and, on the other hand, computer-mediated chat experiments that were purely text-based. The groups' decision topics were taken from public news topics and everyday personal matters. Unsurprisingly, they found that in the text-based chat groups 'participants find it difficult to build trust in this environment' (298). As I understand the experiment, the differences between the experimental setting and the real-life situation of political decision-making seem so evident that the study can hardly count as a study of any communicative figuration, other than that of the laboratory: For instance, the chat-based decision groups used cumbersome text-based computer-mediated communication (CMC) only, and did not include video conferencing, and the experimental participants, presumably with no prior collaborative relations, seem to have little at stake compared with the participants in real-life decision meetings.

Another problematizing discussion (already hinted at above) has to do with the scalability of communicative figurations, and the risk of diluting the concept if the scalability is infinite.

In principle, the scalability of communicative figurations, from the smallest grouping (such as a meeting of a handful of people in a company) to the most complex networked entity (such as the global financial market), follows logically from the definition of the concept. Any entity that can be said to have an actor constellation, a frame of relevance, and a set of communicative practices (with a media ensemble) is a communicative figuration. But, speaking from a position of conceptual formalism, one unintended consequence of the scalability may be that the concept of communicative figuration verges on being empty - if anything can be nominated as a communicative figuration? Perhaps it is worth discussing whether a boundary can be pragmatically set up between rigorously defined, yet flexible communicative figurations, and other forms of social collectivities that are not communicative figurations. 
This said, it is obviously not possible to police the proper use of 'communicative figurations' for analytical purposes; however, it can be suggested that however helpful this conceptual framework may be as a heuristic lens for researching almost any communicative phenomenon, it should perhaps be used more discriminatingly. Maybe a consensus could be reached about what does and what does not constitute a felicitous communicative figuration.

One such core operational area for communicative figurations research could be research which aims to map the cross-media practices in a social domain, in the form of a mapping and explaining their interrelations with media ensembles and repertoires. Many of the case studies in the present volume, ranging from the mapping of the communicative practices of small collectivities (such as groups of friends or institutionally defined groups), over larger community groups and organizations (such as NGOs and educational institutions), to entire country-wide communicative landscapes (such as the news ecology or a national grassroots organization), would fulfil this criterion of carrying out a descriptive and explanatory mapping of a communicative figuration with a definable constellation of actors, common frames of relevance and a set of communicative practices entangled with a media ensemble.

\subsection{Methodological Media-Centrism and Non- Media-Centrism in Figurational Research}

Looking over the analytical methods used in the dozen case studies of communicative figurations in this volume, it is clear there are no prescribed methods in the figurational research community, although a clear preponderance of qualitative methods stands out, especially qualitative interviews in naturalistic settings, but also varieties of ethnographic observation and discourse analysis, often in mixed-method combinations: the reader encounters qualitative interviews (sometimes with photo elicitation or card sorting), participant observation, discourse analysis, quantitative social network analysis, quantitative surveys, quantitative content analysis and qualitative analysis of laboratory experiments. One therefore cannot but applaud the diversity of the methodological toolbox applied by figurational researchers.

Considering that two defining features of deep mediatization are digitization and datafication, it is remarkable there are no full case studies that exploit the tracking capability of online communication, and only 
one study which uses netnography to understand the online communication of actor constellations (Wolf and Wudarski, Chap. 6).

However, in the interesting and reflective Chap. 16, Andreas Breiter and Andreas Hepp discuss digital traces as a controversial methodological challenge for the social sciences in general and for figurational research in particular. The crucial question is 'how we can analyze digital traces in a way that we can contextualize them with the figurations of humans that produce these sequences of "digital footprints" but also use them as a means for social construction' (393). The chapter uses the example of school information systems to discuss in a preliminary way how automatically generated data can be combined with qualitative methods in a mixed-method strategy for the illumination of the given social domain.

To this we may add that as long as society's media ensembles and most people's media repertoires are hybrid constellations of both legacy media and online media, exclusive reliance on the tracking of media users' digital footprints would make the use of all non-digital media disappear from view. Therefore, either researchers will have to overcome the practical technological difficulties of aggregate measurement of individuals' offline and online media use, or a holistic record of people's complete media repertoires will have to be established through quantitative and qualitative forms of self-report methods (Schrøder 2016).

Chapter 15, by Juliane Klein, Michael Walter and Uwe Schimank, is devoted to an immensely inspiring systematic in-depth inquiry into the strengths and weakness of different forms of qualitative interviews for constructing people's cross-media repertoires from the available media ensemble. The general interest of their exploration, beyond optimization of the knowledge interest of their own figurational project, has to do with finding a best practice for the non-mediacentric understanding of media use in the life-world. Following the call for nonmediacentric media research of David Morley (2009); Zlatan Krajina et al. (2014) and others, their study is essentially devoted to the solving of the age-old so-called Observer's Paradox; that is, the fact that the aim of ethnographic research is to find out how people are behaving when they are not being systematically observed-yet this can only be done by observing them systematically (Labov 1972: 209). Therefore, all research that engages people in the collection of data is intrusive and subject to bias. 
The research interest of Klein et al. lies in establishing how media play a part in five life spheres: work, intimate relations, parenthood, asset building, and civil society engagement: 'which role does the interviewees' media repertoires play in their conduct of life with respect to disturbances and coping' (364). In pursuing this aim they are concerned with exploring how the participants' own horizon of relevance can be given priority: what method can ensure a large measure of openness while retaining the researcher's thematic focus on media? The obvious problem faced by many qualitative researchers is that if researchers state their media-focused research interest in their initial framing of the interview and frequently during the course of the interview, 'they might steer the interviewees' response behaviour' (366) and impose a media-centric focus which may not accurately reflect how the interviewees perceive media in the different life spheres.

In order to find a solution to this problem, Klein et al. devise an impressively systematic research design, which takes into account that media-centrism is a continuum. They set up a taxonomic methodological system of media-centrism, which enables researchers to choose the degree of media-centrism that best serves the knowledge interest of their project (Table 15.1: 372). Out of the taxonomy's nine possible interview strategies they select four for experimental testing, with an increasing order of media-centrism:

- Strategy 1: The least mediacentric interview strategy, in which the researcher does not mention media at all, waiting for interviewees to spontaneously bring media into the talk.

- Strategy 3: Media are mentioned in a non-conspicuous way at the beginning of the interview, and are only brought in at the very end after having dealt with the life spheres.

- Strategy 4: Media are mentioned in a non-conspicuous way at the beginning of the interview, and are brought in explicitly after each of the life spheres has been dealt with.

- Strategy 2: Media are emphatically mentioned at the beginning of the interview, and are also brought in explicitly after each of the life spheres has been dealt with.

The analysis of these four interviewing strategies then looked for the prominence that media repertoires displayed in the participants' accounts 
of how they coped with changes in the different life spheres. On this basis, Klein et al. opted for Strategy 4 as the one which best fulfilled their research interest in studying first people's life spheres and secondly the media ensembles drawn into them:

[...]strategy 4 appears to be the one that best suits the purposes of our project. The set stimulus is subtle and thus does not dominate the interviewees' response behaviour, yet it is strong enough to contain the presence of the media topic throughout the interview. Most importantly, this interviewing strategy allows the respondents' individual relevance structures with respect to media and media use as part of their daily routines to be captured. (382-383)

However, other researchers may ask themselves whether Strategy 4 should necessarily be seen as the universal solution to the methodological conundrums of non-mediacentric media research-whether this strategy would be the appropriate one for contributing to their knowledge interest.

For other kinds of figurational research, in which media practices are a more central concern, it can be necessary to be more mediacentric, and still succeed in not being overly mediacentric. For instance, if one is interested in mapping repertoires of cross-media news consumption at the national level, I would think that news media must play a relatively explicit role throughout the interview in order not to risk letting lesser used news sources disappear from view. Moreover, other factors than the interviewer's explicitness in verbalizing media may cause the interviewee to feel at ease or not, and hence affect the extent to which they speak authentically about the role of media in their lifeworld: in general it is of paramount importance to establish a high degree of rapport with the interviewee; more concretely the choice of a domestic versus a more formal (such as a university) location for the interview can affect whether the interview mobilizes undesirable filters on their account of lifeworldwith-the-media experiences.

In my own research, I have opted for something like Strategy 2, because my knowledge interest was somewhat less non-mediacentric (in other words more mediacentric) than that of Klein et al. My knowledge interest was to build insights about people's individual appropriation of the news media ensemble in the national public sphere: how, 
across the many communicative figurations of their lifeworld, deliberately and routinely, they assembled the personal media repertoires which best served their various objectives of democratic and everyday public connection (Couldry et al. 2007), diversion and entertainment, specific instrumental knowledge, and so on (Kobbernagel and Schrøder 2016).

Briefly, therefore, we started our interviews with a solid day-in-thelife conversation in which we pursued in an open manner the sequence of communicative figurations traversed by the interviewee during the course of a day, asking which media were used in them. The interviewee's relevance structures were catered to by adhering to a framework that subtly explored along seven dimensions how the various news media used were experienced as 'worthwhile' by the interviewee. This open stage of the interview was followed by a card-sorting stage, in which interviewees sorted 36 cards representing what we deemed to be the relevant national news media ensemble at the time, according to the role they played in the interviewee's lifeworld. The card sorts were then factor-analyzed using Q-methodological procedure, which resulted in the creation of six news media repertoires, which were further substantiated by excerpts from the interview transcripts.

This is not to say that one interview strategy is inherently better than another. In planning new research into young people's news consumption repertoires under deep mediatization, I could easily imagine adopting, for instance, a narrower interest in online news consumption only, for which a more open methodological approach may be superior. For instance, one could combine the record from the tracking of the participants' digital footprints with qualitative interviews that inquire into the blending of news and other media experiences across communicative figurations in daily life. An additional component could be an open observation of the participants' on-screen navigation with a think-aloud plus interview component.

As I hope to have shown in the comments above, the dozen case studies described in this volume contribute significantly to the understanding of an interesting mosaic of communicative figurations across German society, from the small-scale repair cafés, through the intermediate level of NGOs and public institutions schools, to the national level of the public sphere. They are rich in descriptive details, often demonstrate interesting connections and consequences, and sometimes discover surprising insights about the role of communication media in ongoing 
socio-cultural transformations. As a whole, therefore, the volume is an enriching and innovative contribution to our knowledge about the ways in which communication media make a difference in ongoing crossdomain and cross-media transformations of culture and society.

\section{Notes}

1. Breiter and Ruhe state that 'the micro level of classroom management will be excluded from the analysis' (317). However, the administrative practices of individual teachers, including their use of mobile phones, are traced in group discussions (321).

2. Just as Kramp and Loosen repurpose and reinterpret their previous research to create new insights in a figurational study, it is striking how some classical studies of media practices can retrospectively be seen as analyses of communicative figurations. For instance, James Lull's seminal ethnographic study of the social uses of television can be seen as an analysis of the communicative figuration of the (American) family (Lull 1980); and even more so Janice Radway's similarly ground-breaking study of women's reading of romance novels can be seen as an analysis of the ways in which these media-based collectivities were incrementally transforming gender roles in the early 1980s (Radway 1984). A significant difference, though, is that these two studies did not analyze crossmedia repertoires.

\section{REFERENCES}

Couldry, Nick. 2012. Media, society, world: Social theory and digital media practices. Cambridge: Polity Press.

Couldry, Nick, and Andreas Hepp. 2016. The mediated construction of reality. Cambridge: Polity Press.

Couldry, Nick, Sonia Livingstone, and Tim Markham. 2007. Media consumption and public engagement. Beyond the presumption of attention. Basingstoke: Palgrave Macmillan.

Helles, Rasmus, Jacob Ørmen, Casper Radil, and Klaus B. Jensen. 2015. The media landscapes of European audiences. International Journal of Communication 9: 299-320.

Hepp, Andreas. 2013. The communicative figurations of mediatized worlds: Mediatization research in times of the 'mediation of everything'. European Journal of Communication 28 (6): 615-629. 
Hepp, Andreas. 2014. Communicative figurations. In Media practice and everyday agency in Europe, ed. Leif Kramp, Nico Carpentier, Andreas Hepp, Ilija Tomanić Trivundža, Hannu Nieminen, Risto Kunelius, Tobias Olsson, Ebba Sundin, and Richard Kilborn, 83-99. Bremen: Edition Lumière.

Hepp, Andreas, and Uwe Hasebrink. 2017. How to research cross-media practices? Investigating media repertoires and media ensembles. Convergence: The International Journal of Research into New Media Technologies. First published date: 7 April 2017. doi:10.1177/1354856517700384.

Hjarvard, Stig. 2013. The mediatization of culture and society. New York: Routledge.

Kobbernagel, Christian, and Kim C. Schrøder. 2016. From everyday communicative figurations to rigorous audience news repertoires. A mixed method approach to cross-media news consumption. Mediekultur 32(60): 6-31.

Krajina, Zlatan, Shaun Moores, and David Morley. 2014. Non-media-centric media studies: A cross-generational conversation. European Journal of Cultural Studies 17 (6): 682-700.

Labov, William. 1972. Sociolinguistic patterns. Philadelphia: University of Pennsylvania Press.

Lull, James. 1980. The social uses of television. Human communication research 6: 197-209.

Madianou, Mirca. 2014. Polymedia: Communication and mediatized migration: An ethnographic approach. In Mediatization of communication, ed. Knut Lundby, 323-346. Berlin and Boston: De Gruyter/Mouton.

Morley, David. 2009. For a materialist, non-media-centric media studies. Television and New Media 10 (1): 114-116.

Radway, Janice A. 1984. Reading the romance: Women, patriarchy and popular literature. Chapel Hill: University of North Carolina Press.

Schrøder, Kim C. 2011. Audiences are inherently cross-media: Audience studies and the cross-media challenge. Communication management quarterly 18 (6): $5-27$.

Schrøder, Kim C. 2016. Q-method and news audience research. In The SAGE handbook of digital journalism, ed. Tamara Witschge, C.W. Anderson, David Domingo, and Alfred Hermida, 528-546. Los Angeles, CA: Sage.

Strömbäck, Jesper. 2008. Four phases of mediatization: An analysis of the mediatization of politics. The International Journal of Press/Politics 13 (3): 228-246.

Taneja, Harsh, James G. Webster, Edward C. Malthouse, and Thomas B. Ksiazek. 2012. Media consumption across platforms: Identifying user-defined repertoires. New Media and Society 14 (6): 951-968. 
Open Access This chapter is licensed under the terms of the Creative Commons Attribution 4.0 International License (http://creativecommons.org/licenses/ by $/ 4.0 /$ ), which permits use, sharing, adaptation, distribution and reproduction in any medium or format, as long as you give appropriate credit to the original author(s) and the source, provide a link to the Creative Commons license and indicate if changes were made.

The images or other third party material in this chapter are included in the chapter's Creative Commons license, unless indicated otherwise in a credit line to the material. If material is not included in the chapter's Creative Commons license and your intended use is not permitted by statutory regulation or exceeds the permitted use, you will need to obtain permission directly from the copyright holder.

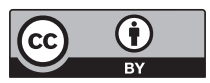

